\title{
Formação inicial e continuada de professores de Português Língua Estrangeira/Segunda Língua no Brasil
}

\author{
Jessica Chagas de Almeida* \\ Nildicéia Aparecida Rocha**
}

A coletânea de $\operatorname{artigos}^{1}$ organizada por Scaramucci e Bizon oferece um panorama no âmbito da formação inicial e continuada de professores de português língua estrangeira (PLE) e de português segunda língua (PSL ou PL2), envolvendo as quatro licenciaturas já institucionalizadas no Brasil e de outros programas importantes que dispõem de iniciativas de formação de professores.

A compilação reúne textos de autores consolidados na área de PLE/PL2 no Brasil e internacionalmente. Quando nos referimos à "área de PLE/PL2", remetemos à noção de um campo de saber, de conhecimento. Portanto, são professores, pesquisadores, agentes políticos de consolidação, divulgação e projeção desse campo de saber que, por sua vez, é fortalecido por tais iniciativas.

Ressaltamos a relativa atualidade dessa área no Brasil, visto que é ao final dos anos 1980 que surgem os primeiros sinais de emergência de instituição e institucionalização do $\mathrm{PLE}^{2}$ como campo de conhecimento (ALMEIDA FILHO, 2012); "na área

\footnotetext{
* Faculdade de Ciências e Letras - FCLAr/UNESP, Doutora em Linguística e Língua Portuguesa, professora de PLE, https:// orcid.org/0000-0002-9237-8224.

** Faculdade de Ciências e Letras - FCLAr/UNESP, Livre Docente em PLE, Professora Doutora Associada, https://orcid. org/0000-0003-3815-3785

1 Referência completa da obra aqui resenhada: SCARAMUCCI, M. V. R.; BIZON, A. C. C. (org.). Formação inicial e continuada de professores de Português Língua Estrangeira/Segunda Língua no Brasil. Araraquara: Letraria, 2020.

2 Neste texto, não fazemos distinção entre os termos segunda língua (L2), língua estrangeira (LE) e língua adicional (LA). Em função do próprio título do livro, optamos pela utilização de LE e L2 de modo geral. O termo LA aparece conforme a utilização dos autores ao longo dos capítulos.
} 
de ensino/aprendizagem, PLE talvez tenha entrado por último na pesquisa no Brasil" (CAVALCANTI, 2020, p. 9). Assim, a obra se mostra pertinente por atuar como consolidadora das pesquisas em torno do PLE no Brasil, que, dada à sua novidade, tem várias páginas omissas em sua história (ALMEIDA FILHO, 2015) e, por esse motivo, tem sua existência em plena constituição.

Particularmente nos anos 2000, há um aparente incentivo às pesquisas em torno do desenvolvimento da área de PLE/PL2, impulsionado pelas relações sociais, geopolíticas, econômicas que prezam pela internacionalização das línguas; em outras palavras, o intercâmbio linguístico é fomentado pelas condições sócio-históricas de globalização, o que incentiva que as línguas circulem em diversos espaços de enunciação (GUIMARÃES, 2006). Assim, diferentes demandas para o ensino e aprendizagem emergem e impulsionam a criação de dispositivos políticos de organização das línguas, como a criação de materiais didáticos, ementas, cursos livres e, no caso, formação de professores.

Com o objetivo de construir um retrato parcial da área, os artigos perpassam, também, distintas realidades do território brasileiro, no que concerne ao reconhecimento e à consolidação de ações em prol da constituição da formação de professores e a emergência de seus contextos específicos. Por conseguinte, os artigos adicionam ao escopo do PLE/PL2 diversas e contemporâneas demandas de ensino, em relação ao movimento atual de mobilidade de minorias, como os cenários de migração, cenários de fronteiras, cenários de surdez e cenários indígenas.

Neste momento de "virada linguística", que contribui significativamente para a "utilidade ou relevância social dos estudos linguísticos" (OLIVEIRA, 2007), destacamos, ainda, publicações que contribuem com as iniciativas de fortalecimento 
de pesquisas em PLE/PL2 no Brasil, particularmente no ano de 2020, que têm as organizadoras como colaboradoras: o Documento base do exame Celpe-Bras (BRASIL, 2020a), publicado pelo INEP (Instituto Nacional de Estudos e Pesquisas Educacionais Anísio Teixeira), que conta com Scaramucci para a elaboração do texto; e a coleção Proposta curricular para o ensino de português nas unidades da rede de ensino do Itamaraty em países de língua oficial espanhola, elaborada pelo Ministério das Relações Exteriores, com a participação de Bizon no primeiro volume da série (BRASIL, 2020b).

A coletânea é um registro histórico-didático-curricular inédito no Brasil e está organizada em duas partes após o prefácio e a apresentação: a primeira parte, intitulada "A formação do professor nas licenciaturas em PLE/PL2", e a segunda, denominada "Ações de ensino e de formação do professor em outros programas de PLE/PL2".

De modo geral, apresentam as ações de formação de professores em cada instituição, um registro histórico da criação da área nas instituições e as concepções teóricas que fundamentam o ensino e a formação de professores em seus contextos.

A organização da coletânea obedece à ordem cronológica de criação das licenciaturas. Destacamos que, de forma comum, as quatro licenciaturas denominam a área como PLE/PL2, ainda que reconheçam, no corpo do texto ou em forma de comentário, a multiplicidade de denominações.

Assim, iniciamos a leitura da primeira parte da coletânea. O primeiro artigo, "A licenciatura em PBSL e o Programa de PLE na Universidade de Brasília: histórico, desafios e perspectivas", é assinado por Marcia Niederauer, Ana Adelina Lopo Ramos, 
Flávia Maia-Pires e Verônica Vinecký. A licenciatura, na Universidade de Brasília (UnB), foi criada em 1997 e forma professores para atuarem, sobretudo, no contexto de ensino de português como segunda língua - como o próprio nome da licenciatura supõe. Mais especificamente, a necessidade do curso surge da grande demanda de estudantes e pesquisadores na universidade, da comunidade internacional residente em Brasília em representações diplomáticas e da necessidade da existência de português para surdos e indígenas.

As autoras iniciam com um percurso histórico da criação da licenciatura e seguem com uma descrição dos docentes e discentes do curso, levando em conta questões políticas, de identidade e de representação que integram o cenário linguístico no Brasil. Em seguida, descrevem a estrutura curricular do curso e outros projetos de formação e enfocam alguns deles para aprofundarem a discussão. Em relação às ações de apoio, destacam-se projetos desenvolvidos por docentes dentro da universidade e em nível internacional. Por fim, encerram o artigo realizando um levantamento geral das ações, no âmbito científico, realizadas no interior da UnB, como dissertações e teses, e reafirmando a pertinência da Licenciatura em PBSL na UnB e no Brasil.

O segundo artigo é de Edleise Mendes e se intitula "A licenciatura em PLE/PL2 na Universidade Federal da Bahia: formando professores para a diversidade". Iniciado em 2005, este curso não oferece dupla habilitação em língua materna e estrangeira, como é comum em diversos cursos de Letras. As pesquisas sobre PLE/PL2, na UFBA, são realizadas no interior de seu Programa de Pós Graduação em "Língua e Cultura", e esse dado dá uma indicação do rumo descritivo operado no texto por Mendes. 
Após começar com a reconstrução da história de criação da licenciatura, caracterizando diversas ações em prol da construção do curso, a autora inicia com foco na formação de professores na UFBA, cujo objetivo é "formar professores para a diversidade", isto é, formação de egressos que explorem a compreensão da língua em sua dimensão social e interacional, como ação situada culturalmente. De fato, é dada grande ênfase à dimensão cultural na formação de professores na UFBA, visto que Mendes estabelece um retrato teórico da concepção epistêmica que embasa a licenciatura em PLE/PL2 na UFBA. Após descrever a grade curricular do curso, a autora encaminha às "palavras finais", em que ressalta a importância de formação de professores com sensibilidade cultural.

Posteriormente, o artigo "A licenciatura em PLE na Universidade Federal da Integração Latino-Americana" discorre sobre o curso de licenciatura em Letras-Espanhol e Português como Línguas Estrangeiras da Universidade Federal da Integração Latino-Americana (Unila). Criada em 2010, a Unila surge com o intuito de favorecer a integração sul-americana e, por conseguinte, tem como tripé "bilinguismo, interculturalidade e interdisciplinaridade". O artigo é assinado por Tatiana Pereira Carvalhal e inicia com a caracterização da universidade, em relação à integração, fronteira e dados gerais dos objetivos da Unila.

Em seguida, Carvalhal descreve o curso de Letras da Unila, levando em conta os objetivos da Unila para implementação da proposta curricular e perfil do público-alvo. Em relação à organização curricular, Carvalhal esclarece que o curso está dividido em três eixos fundamentais: Eixo Linguagens, Eixo Pedagógico e Eixo Interdisciplinar, que consideram aspectos 
culturais, sociais, econômicos, ambientais e políticos da América Latina. À guisa de conclusão, são apresentadas as características de formação crítica de professores e suas potencialidades de contribuição para a formação de professores de PLE diante das particularidades da Unila.

Por fim, Matilde V. R. Scaramucci e Ana Cecilia Cossi Bizon são as autoras de "O PLE na Unicamp: da implantação da área à formação de professores". O ensino de PLE/PL2 na Unicamp tem início concomitante à própria criação da universidade, ainda nos anos 1970. Porém, é apenas em 2017 que se dá a efetiva implementação da habilitação em PLE. Nesse artigo, as autoras registram a trajetória da área de PLE na Unicamp a partir do que empreendem como gestos de políticas educacionais e de línguas.

Assim, o primeiro gesto apontado é o de reconhecimento da necessidade de se ensinar PLE na Universidade de Campinas, nos anos 70, à comunidade docente que se integrava à instituição. $\mathrm{O}$ segundo gesto consiste na descrição de ações para a consolidação do ensino da pesquisa e de políticas públicas e de línguas; aqui, destacam-se as ações de ensino promovidas no âmbito da extensão e de seminários, congressos e encontros desenvolvidos na Unicamp, além dos diversos motivadores políticos, como: a fundação e organização dos primeiros seminários da Sociedade Internacional Português Língua Estrangeira (Siple); o desenvolvimento do Exame de Proficiência em Português para Estrangeiros que culminou com a consolidação do exame CelpeBras; e outros projetos em cooperação com o Ministério da Educação. Finalmente, as autoras apontam o terceiro gesto, que se trata do reconhecimento de formar professores. É a partir desse terceiro gesto que o curso é caracterizado, primeiramente, com um histórico da implementação da segunda habilitação em PLE/ 
PL2. Em seguida, a estrutura curricular e o perfil dos egressos compõem o momento em que as autoras explicitam as premissas do curso. As autoras finalizam ressaltando a importância de criação de mais licenciaturas com compromisso teórico-prático.

A segunda parte da coletânea traz à luz ações sobre o ensino e a formação docente de outros programas de PLE/PL2, em especial da Universidade Federal do Rio Grande do Sul (UFRGS), da Universidade Federal do Rio de Janeiro (UFRJ), da Universidade Federal do Paraná (UFPR), da Universidade Federal de Minas Gerais (UFMG) e da Universidade Federal do Amazonas (UFAM).

Margarete Schlatter, Gabriela da Silva Bulla e Everton Vargas da Costa são os autores do primeiro texto da segunda parte, intitulado "A identidade do professor-autor em construção no diálogo entre profissionais mais e menos experientes na UFRGS", que objetiva apresentar um contexto profícuo na formação de professores, na atuação autoral e crítica e na construção da identidade profissional por meio de diálogos histórica e culturalmente dados. Para tal, inicia traçando os 25 anos do percurso e das ações em PLE que estão marcados por serem espaços de "formação inicial e continuada de professores de Português como Língua Adicional (PLA)" (p. 115), com o intuito de promover nesse percurso uma prática reflexiva.

Na UFRGS, a área de PLE tem seu marco com a criação de um programa extensionista, o Programa de Português para Estrangeiros (PPE), no início dos anos 90, para desenvolver pesquisa, ensino e formação de professores. Hoje, a Licenciatura em Letras conta com duas disciplinas eletivas em PLE, uma disciplina obrigatória e estágio supervisionado. O PPE parte de quatro eixos fundamentais para a formação da identidade 
profissional, a saber: promoção do ensino; prática reflexiva; promoção de pesquisa sobre a prática; e registro escrito das aprendizagens. Assim, o programa promove "a escuta, o diálogo e a reflexão conjunta" no intuito de incentivar o "exercício da autoria" (p. 126), apresentado por meio de um evento que focaliza o planejamento colaborativo de aulas em PLA, na quarta subseção do texto. Nas considerações finais, os autores enfatizam a importância de promover as reflexões sobre identidade e autoria em ser professor, assim como o diálogo constante e contínuo entre os sujeitos envolvidos no processo de ensino e aprendizagem.

No texto "Ações de política de formação de professores em PLE na Universidade Federal do Rio de Janeiro", de Patricia Mara Campos de Almeida, Danúsia Torres dos Santos, Andrea Lima Belfort-Duarte e Ana Catarina Moraes Ramos Nobre de Mello, registram-se as ações contemporâneas desenvolvidas na Universidade Federal do Rio de Janeiro, da Faculdade de Letras, as quais oferecem ao graduando "conhecimentos teóricos e práticos" na área de PLE. Apresenta-se em quatro partes, a saber: ações do Setor de Português Língua Estrangeira na graduação; espaços na extensão; o pré-PEC-G; e o Idiomas sem Fronteiras (IsF).

Em um movimento de políticas na formação de professores de PLE e a partir de uma perspectiva que acompanhe o atual contexto das políticas curriculares, das exigências de novos curricula e das novas imposições da atualidade, a Faculdade de Letras da UFRJ insere a disciplina obrigatória de Português Língua Estrangeira, assim como disciplinas optativas na área, organizadas pelos docentes do Setor de Português Língua Estrangeira (Seple), com o intuito de propiciar ao graduando um 
percurso formativo e como iniciativas de formação inicial em PLE. Referente à formação complementar, o Seple oferece, para além da formação inicial, um rol de atividades que focalizam as práticas docentes em PLE, para além dos aspectos teóricos e a pesquisa. A Faculdade de Letras conta também com outros programas nos quais se inserem os docentes do Seple: o Programa de Ensino e Pesquisa em Português para Estrangeiros (Peppe), Programa Estudante Convênio de Graduação (PEC-G) e Idiomas sem Fronteiras - Português (IsF-Português).

Desse modo, assim como várias instituições, as ações na UFRJ relacionadas à área de PLE também se iniciaram no âmbito da extensão desde os anos 1970, as quais têm se ampliado e consolidado ao longo das últimas décadas. Algumas dessas ações são: reuniões de orientação semanais, cursos especiais e intensivos, Jornada Interna de Formação do Peppe, Seminário do Programa de Ensino e Pesquisa em Português para Estrangeiros, entre outras. As autores, portanto, por meio da focalização das atuais ações, recuperam a história da área de PLE na Faculdade de Letras da UFRJ e registram as diversas e relevantes ações políticas para a consolidação da área no âmbito institucional.

Resgatando a história das ações em PLE que se iniciaram a partir das parcerias internacionais, os autores Bruna Pupatto Ruano, Francisco Javier Calvo Del Olmo e Mariza Riva de Almeida, no terceiro capítulo da segunda parte deste inédito livro, apresentam o texto "A implementação da formação de professores de PLE na UFPR: percursos e práticas nos eixos da extensão, da pesquisa e do ensino". Observada a necessidade de se instaurar ações em PLE, uma das primeiras atividades foi oferecer cursos de PLE para estudantes estrangeiros e, logo em seguida, também cursos sobre a área para os alunos de Letras 
e docentes interessados. A criação do Centro de Línguas e Interculturalidade (Celin) da UFPR foi fundamental para a implementação e consolidação de PLE na instituição, em meados dos anos 90, e sob a perspectiva da inter-relação indissociável entre língua e cultura. O projeto de PLE no Celin pôde promover muitas práticas em PLE pautadas em uma aprendizagem colaborativa e na "construção de conhecimento compartilhado" entre formadores e professores-em-formação" (p. 165).

A pesquisa e a criação de grupos de pesquisa também estão presentes e constantes na UFPR relacionadas à área de PLE, como, por exemplo, o projeto Multiletramento, no contexto de ensino de PLE, o projeto Produção e avaliação de materiais didáticos para ensino de PLE, entre outros. E, no processo de institucionalização da área de PLE, a partir da internacionalização das universidades brasileiras, implementam-se disciplinas optativas em PLE também na graduação, assim como orientações de trabalhos de conclusão de curso (TCC). Nesse mesmo sentido, desde 2014, vem sendo ofertadas disciplinas de Pós-Graduação na área de PLE junto aos programas da UFPR, em geral, sendo ministradas por especialistas da própria universidade e por especialistas convidados de outras instituições, resultando na produção de dissertações e teses na área de PLE. Os autores apresentam ainda, por um lado, a organização e o oferecimento, a partir de 2019, de um Curso de Especialização em Formação de Professores de Português como Língua Estrangeira e Culturas Lusófonas (online). Por outro lado, apresentam o Projeto de Extensão intitulado "Projeto Português Brasileiro para Migração Humanitária" (PBMIH), que tem a "concepção de um programa de ensino, pesquisa e extensão de português brasileiro voltado a migrantes na condição de refugiados e/ou em situação de vulnerabilidade 
social"(p. 174). As atividades didáticas desenvolvidas no âmbito da língua de acolhimento são realizadas pelos alunos da Pós-Graduação em Letras da UFPR sob a coordenação de especialistas da área de PLE da universidade.

Ao finalizar o texto, os autores enfatizam a emergência e necessidade de se contratar docentes especialistas na área de PLE na universidade e também para a formação de professores de PLE, entre outras questões propostas, dando ênfase à premência em se registrar as ações em PLE que estão sendo desenvolvidas nas universidades brasileiras.

O penúltimo texto dessa coletânea, assinada por Leandro Rodrigues Alves Diniz e Regina Lúcia Péret Dell'Isola, denominado "Percursos de institucionalização da área de Português como Língua Adicional na Universidade Federal de Minas Gerais", tem o objetivo de registrar os percursos pelos quais foi se construindo a área de PLE na referida instituição, como o próprio título o apresenta, a partir da (re)construção de uma "memória" como um gesto de interpretação, perpassada por reminiscências e apagamentos. Os autores iniciam especificando a escolha pelo termo "Português como Língua Adicional (PLA)", no sentido de que tal termo permite "visibilizar a heterogeneidade linguística constitutiva de um país como o Brasil, onde muitos indígenas, surdos e imigrantes não têm o português como primeira língua" (p. 181-182). O percurso discursivo do texto está estruturado em quatro seções que apresentam as ações de PLA na Extensão, no Ensino, na Pesquisa e as mais recentes, que se vinculam a grupos minoritarizados.

Segundo Diniz e Dell'Isola, as ações de extensão vinculadas à área de PLA datam desde a década de 1980, oferecendo cursos semestrais pelo Centro de Extensão (Cenex) da Faculdade de 
Letras (Fale), sendo coordenados por professores e ministrados por alunos bolsistas da referida graduação. Algumas ações na área de PLE estão vinculadas ao Programa Intensivo de Língua Portuguesa e Cultura Brasileira, que oferece cursos em caráter regular e intensivo para diversos contextos e níveis. Outra importante ação é o Curso para Candidatos ao Programa de Estudantes-Convênio de Graduação, também oferecido pelo Cenex, além disso, esse Centro também é posto aplicador do exame de proficiência Celpe-Bras.

Especificamente no ensino, a área de PLA está presente em disciplinas oferecidas à comunidade internacional que não tem português como primeira língua. Além disso, os autores trazem quadros que exemplificam as disciplinas em PLA ofertadas em Curso de Graduação em Letras e na Pós-Graduação em Estudos Linguísticos da Fale. Desde os anos de 2011/2012, funciona o Núcleo de Ensino e Pesquisa em Português Língua Adicional (Neppla), que tem desenvolvido um importante volume de estudos na área de PLA, assim como o Núcleo de Estudos em Libras, Surdez e Bilinguismo (Nelis), com ações especificadas e apresentadas em quadros nas páginas de 198 a 201. Os autores fecham o texto reconhecendo o relevante avanço da área na universidade nos últimos anos, mas enfatizam a necessidade de ampliar a área tanto na UFMG como em nível nacional e internacional, para assim dar maior visibilidade às práticas em PLA.

O texto "Ensino de PLE e formação de professores na Universidade Federal do Amazonas", escrito por Maria Regina Marques Marinho, Valéria Moisin Araújo e Wagner Barros Teixeira, é o último dessa obra tão urgente e necessária na atualidade dos estudos em PLE/PLA. Os autores desse texto 
partem da formação da universidade, a primeira a ser fundada no Brasil, em 1909, para contextualizar suas ações em PLE, que dão voz a aproximadamente 50 línguas indígenas e às línguas alóctones, como o inglês, o francês, o japonês e o coreano, na região. Inserida nesse "mosaico amazonense multilinguístico", a língua portuguesa define-se como língua materna, adicional - L2 (indígenas e imigrantes), língua estrangeira (indígenas e turistas/visitantes) e língua de acolhimento (sujeitos em situação de refúgio). Assim, a Ufam oferece diversas ações na área de PLE para atender a esses diferentes aprendizes, desde cursos de Graduação em Letras (oito cursos), de formação continuada em especialização e mestrado, a cursos livres para a comunidade, que são ministradas pelos acadêmicos de Letras. Os autores dão destaque também às ações desenvolvidas para atender ao público proveniente de parcerias internacionais com universidades estrangeiras, assim como no PEC-G e no PEC-PG, etc., os quais podem ser contemplados na Tabela 1 do texto (p. 216). A Ufam também é posto aplicador do exame Celpe-Bras, desde 2002, para oportunizar a comprovação de proficiência em português ao público que recebe. Segundo os autores, as ações em PLE são desenvolvidas junto ao Centro de Línguas (CEL), instituído nos anos 90, que oferece cursos de várias línguas estrangeiras, dentre elas os de PLE, e também no Núcleo de Línguas (Nucli) do Idiomas sem Fronteiras, criado em 2015.

Os autores reforçam a perspectiva plural e multilíngue da região amazonense e entendem que suas ações em línguas estrangerias, em especial em PLE, partem de políticas linguísticas de incentivo, consolidação e difusão das ações em nível de ensino, da extensão e de pesquisas nas línguas que coexistem em seu território. 
Uma vez apresentados os capítulos que compõem esse livro, sendo a primeira parte composta pelas universidades brasileiras que oferecem cursos de Licenciatura em Português Língua Estrangeira, e a segunda parte, pelas variadas ações em PLE em universidades de norte a sul do Brasil, textos ricos em detalhes e especificidades segundo as realidades aqui enfocadas, convidamos os leitores a incursionarem pelas veredas da língua portuguesa como língua estrangeira/como língua adicional nessas prazerosas páginas de tocantes e diversas práticas educativas, institucionais e sócio-históricas, como um resgate e registro de uma memória em PLE.

Recebido em: 26/04/2021 // Aceito em: 28/04/2021

\section{Referências}

ALMEIDA FILHO, J. C. P. A página omissa: contribuições para uma história do ensino de línguas no Brasil. Revista EntreLínguas, Araraquara, v. 1, n. 2, p. 195-202, 2015.

ALMEIDA FILHO, J. C. P. Ensino de português língua estrangeira/EPLE: a emergência de uma especialidade no Brasil. In: LOBO, T. et al. (org.). Rosae: linguística histórica, história das línguas e outras histórias [on-line]. Salvador: Edufba, 2012. p. 723-728.

BRASIL. Documento base do exame Celpe-Bras. Brasília: Instituto Nacional de Estudos e Pesquisas Educacionais Anísio Teixeira, 2020a.

BRASIL. Proposta curricular para o ensino de português nas unidades da rede de ensino do Itamaraty em países de língua oficial espanhola. Brasília: Funag, 2020b. 
Formação inicial e continuada de professores de Português Língua Estrangeira/Segunda Língua no Brasi

CAVALCANTI, M. C. Prefácio. In: SCARAMUCCI, M. V. R.; BIZON, A. C. C. (org.). Formação inicial e continuada de professores de Português Língua Estrangeira/Segunda Língua no Brasil. Araraquara: Letraria, 2020. p. 9-10.

GUIMARÃES, E. Espaço de enunciação e política de línguas no Brasil. In: OLIVEIRA, S. E.; SANTOS, J. F. (org.). Mosaico de linguagens. Campinas: Pontes/Cellip, 2006. p. 47-53.

OLIVEIRA, G. M. A "virada político-linguística" e a relevância social da linguística e dos linguistas. In: CORREA, D. A. (org.). A relevância social da Linguística: linguagem, teoria e ensino. São Paulo: Parábola Editorial, 2007. p. 79-93.

SCARAMUCCI, M. V. R.; BIZON, A. C. C. (org.). Formação inicial e continuada de professores de Português Língua Estrangeira/Segunda Língua no Brasil. Araraquara: Letraria, 2020 . 